\title{
A Study on Search Strategies of Netted Surveillance Radar
}

\author{
Fei Li,
}

School of Electronics and Information

Northwestern Polytechnical University

Xi'an, Shanxi Province, China

nwpulf@mail.nwpu.edu.cn

\section{XiaoGuang Gao}

School of Electronics and Information

Northwestern Polytechnical University

Xi'an, Shanxi Province, China

nwpulf@mail.nwpu.edu.cn

\begin{abstract}
Aiming at the netted radar surveillance problem, an intelligent search strategy is put forward. Firstly the target's probability values is given, by ESM pre-search the specified airspace surveillance, as the target distribution weights; Then based on the optimization criterion of maximizing the weighted probability of detection, the distribution function of radar-target is built and the algorithm is given; Finally, the feasibility of the method is verified through MATLAB simulation experiment. The content of this paper can provide theoretical guidance for the actual engineering application.
\end{abstract}

Keywords-netted surveillance radar; weak maneuvering target; weighted searching probability; MATLAB simulation

\section{INTRODUCTION}

Radar theory has been a vibrant scientific field for the last 50 years or so [1-3]. Radar theory deals with many different and diverse problems. However, the two most important problems are the detection and range estimation problems. The importance of these two problems is not limited to radars, and other engineering disciplines like sonar and communication deal with very similar problems [4]. Over the years, radar systems have developed considerably. These developments can be attributed to the increase in computation power and advances in hardware design. While early radar systems utilized a directional antenna, today's array radar systems can synthesize beams and simultaneously scan the whole space $[5,6]$.

With the development of military technology, network operations and group battles have gradually become the main form in the future war[7]. Timely information acquisition of multi-sensor multi-target will become the key to victory in the war. From the current application [8], radar network monitoring the designated airspace, realtime monitoring of invasion of the enemy target, have become a hot topic in the construction of air defense sensor network[9]. As a result, effective and reasonable distribution of radar network for the detection of invaded target in order to find them as soon as possible becomes a key technology in the construction of air defense radar network[10].

\section{PROBLEM DESCRIPTION AND MODELING}

\section{A. Problem description}

In the future air defense system, the ground-based air defense radar and electronic support equipment (ESM) compose large-scale air defense network [11]. It monitors the designated airspace, searches, detects and tracks the invaded targets. Fusion result is transmitted to the ground control center [12]. The control center makes quick decision based on the results received and takes a series of measures to the enemy targets. As shown in Fig.1, electronic support equipment continuously scans the entire airspace. Once the invaded target is found, ESM namely guides the ground-based radar to scan the designated airspace in higher accuracy. At the same time, the ESM continues the search task. After receiving the command guidance of ESM, the ground-based radar network detects specific airspace according to certain search strategies of network search [13]. Once the enemy target is found, the tracking radar starts to work to track the target and the tracking results are transmitted to the ground control center. The search process continues until all the targets are detected accurately.

Consider the following scenario: At some point, $\mathrm{N}$ targets are found by ESM. Due to the low resolution of ESM, the target information cannot be measured accurately. The ESM can only divide the rough area of target existence in the form of probability. In order to achieve the goal of effective interception, air defense radar network detects the suspected area under the guidance of ESM to determine the target. 


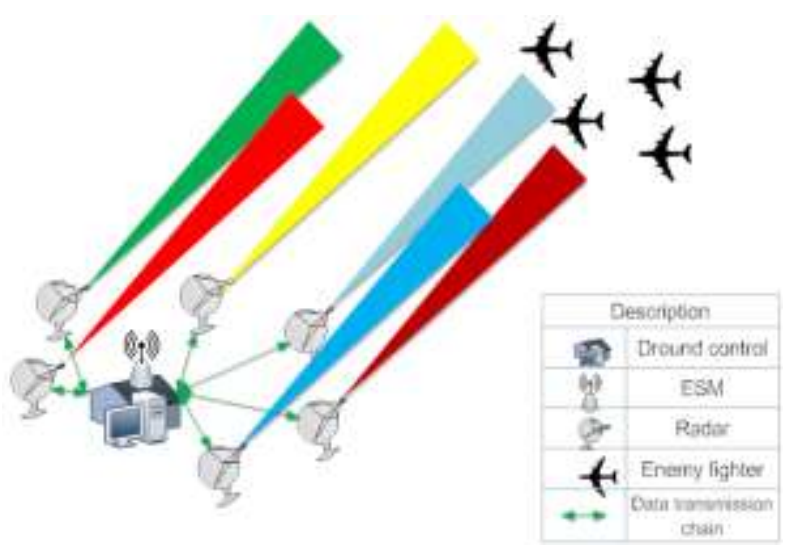

Figure 1. Surveillance radar net

The division of the target area must meet two conditions: 1) the search area must be able to cover the target; 2) the impact of motion characteristics of target on the search area must be considered [14]. If the target is weak maneuvering target, which means the target does not make large-scale maneuver during the netted radar search cycle. When making a search strategy, we assume that the object exists and the region all the time. It only needs to select the specific radar subnet and assign specific airspace for detecting in such circumstances [15]. This is a multi-sensor multi-target assignment problem; if the target is maneuvering target, which means the target may move out of the area divided by the ESM during the netted radar search cycle. So, when making the search strategy, the changing of the search area influenced by the target maneuvering must be considered. In this case, the search area must be divided dynamically, so is the target distribution [16].

In order to achieve effective search to a specific airspace, radar network needs to scan multiple target area in higher detection probability [17]. Radar detection probability is relevant to the radar radiation time and number of radar netting. The irradiation time is longer and the number of netted radar is bigger, the detection probability is corresponding larger. Because the search time and radar numbers are limited, the decision should be made to maximize the detection probability within the limitation of the search time, the number of radars and the target coverage limit, in order to find the target as soon as possible.

\section{B. Problem modeling}

\section{1) Objective weights}

Assuming that ESM performs a search and founds $n$ targets, the target area is given as well as the existence probability. As shown in Fig.2.

$T_{i}$ indicates targets. The white region indicates the target area divided by ESM, its existence probability is expressed as $p_{i}$

$$
p_{i}(t)=\left(p_{1}(t), p_{2}(t) \cdots p_{n}(t)\right)
$$

2) Netted radar searching probability radar: $p_{f a}$ is false-alarm probability. $S N R$ is radar receiver's signal-to-noise ratio calculated by radar equation[8,9]:

$$
. S N R=\frac{P_{a v} G_{t} G_{r} \lambda^{2} \sigma}{(4 \pi)^{3} k T_{0} F_{n} L R^{4}}
$$

$P_{t}$ is radar transmitting power $(W) ; G_{t}$ is the transmitting antenna gain; $G_{r}$ is the receiving antenna gain; $\lambda$ is the radar wavelength $(m) ; \sigma$ is the RCS $\left(\mathrm{m}^{2}\right)$ of the target; $k$ is the Boltzmann constant $\left(k=1.38 \times 10^{-23} \mathrm{Ws} / K\right) ; B$ is the receiver bandwidth $(\mathrm{Hz}) ; T_{0}$ is the receiver noise temperature at room temperature $\left(T_{0}=290 k\right) ; F_{n}$ is the receiver noise coefficient; $L$ is the radar system loss; $R$ is the radar range.

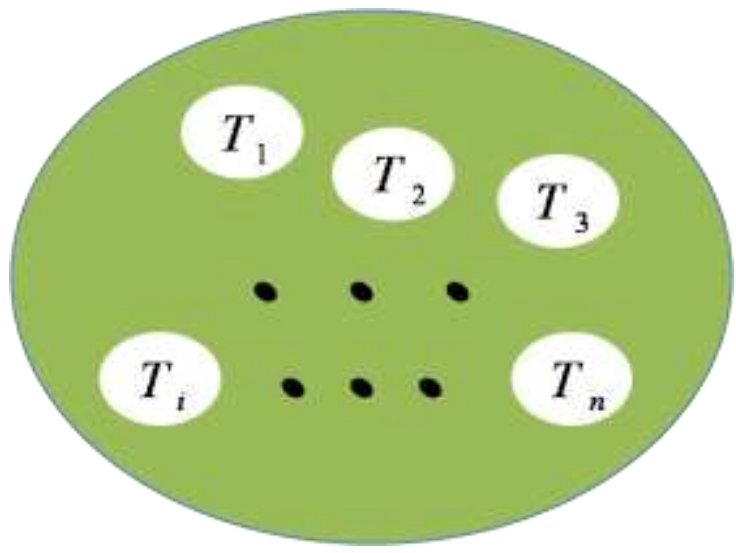

Figure 2. The target area

From the above formula, the accumulation detection probability of $M$ scans of $i$ radar can be deduced:

$$
p_{i D}=1-\left(1-p_{i d}\right)^{M}
$$

Cumulative probability of $M$ scans of $N$ radars shown as:

$$
p_{N D}=1-\prod_{i=1}^{N}\left(1-p_{i D}\right)
$$

3) Optimization model

The whole search process needs to satisfy the following constraints [18]:

- Detection probability: The detection probability of radar network must achieve certain value while detecting designated airspace and at the same time the probability of false alarm should also be limited under certain value.

- Search time: Radar air defense network is real time air defense network. Once the target is found, the system must finish detecting and tracking task in a very short time in order to start the subsequent fire attack. Therefore, the search time of the radar net must be restricted in a certain range.

- Moreover, the radar power also is a constraint. Because it belongs to the micro-optimization process, it is no longer the scope of this article. 
As a result, radar network must detect all targets as soon as possible within the constraints mentioned above. Therefore, the detection probability is selected as the optimization objective and the corresponding search model is established. The derivation is as follows.

Suppose there are $n$ targets and $m$ radars. The needed detection probability is $Q_{D}$.

Firstly, the final detection probability of radar net towards specific airspace should be the objective weights provided by the ESM multiply the detection probability of radar network itself. Here, we call it weighted detection probability $q_{D}$ :

$$
q_{D}=p_{i} \bullet p_{N D}
$$

The weighted detection probability should be greater than the needed detection probability:

$$
q_{D} \geq Q_{D}
$$

The optimal objective is maximizing the weighted detection probability within the constraint of the needed minimum detection probability. Combining the optimization function and constraint conditions mentioned above, the final optimization model is obtained:

$$
\begin{aligned}
& \max f=\sum_{i=1}^{n} q_{D} \\
& \text { s.t. } q_{D} \geq Q_{D}
\end{aligned}
$$

\section{ALGORITHM RESEARCH}

Aiming at the model established above, an improved multidimensional nonlinear algorithm is proposed to solve the problem. To illustrate this, we assume there are 10 radars and 5 targets. As shown in table 1.

TABLE I. RADARS AND5 TARGETS

\begin{tabular}{|c|c|c|c|c|c|}
\hline R\T & T1 & T2 & T3 & T4 & T5 \\
\hline R1 & X11 & X12 & X13 & X14 & X15 \\
\hline R2 & X21 & X22 & X23 & X24 & X25 \\
\hline R3 & $\mathrm{X} 31$ & $\mathrm{X} 32$ & $\mathrm{X} 33$ & $\mathrm{X} 34$ & $\mathrm{X} 35$ \\
\hline R4 & $\mathrm{X} 41$ & $\mathrm{X} 42$ & $\mathrm{X} 43$ & $\mathrm{X} 44$ & $\mathrm{X} 45$ \\
\hline R5 & $\mathrm{X} 51$ & $\mathrm{X} 52$ & $\mathrm{X} 53$ & $\mathrm{X} 54$ & $\mathrm{X} 55$ \\
\hline R6 & $\mathrm{X} 61$ & $\mathrm{X} 62$ & $\mathrm{X} 63$ & $\mathrm{X} 64$ & $\mathrm{X} 65$ \\
\hline R7 & $\mathrm{X} 71$ & $\mathrm{X} 72$ & $\mathrm{X} 73$ & $\mathrm{X} 74$ & $\mathrm{X} 75$ \\
\hline R8 & $\mathrm{X} 81$ & $\mathrm{X} 82$ & $\mathrm{X} 83$ & $\mathrm{X} 84$ & $\mathrm{X} 85$ \\
\hline R9 & $\mathrm{X} 91$ & $\mathrm{X} 92$ & $\mathrm{X} 93$ & $\mathrm{X} 94$ & $\mathrm{X} 95$ \\
\hline R10 & $\mathrm{X} 101$ & $\mathrm{X} 102$ & $\mathrm{X} 103$ & $\mathrm{X} 104$ & $\mathrm{X} 105$ \\
\hline
\end{tabular}

$\mathrm{X}_{\mathrm{ij}}$ indicates whether the radar detects the target or not. If the value is 1 , the radar I detects target $\mathrm{j}$. if the value is 0 , the radar I does not detect the target $\mathrm{j}$. Based on the coverage requirements that each target must be detected, we can obtain the following relationship:

$$
\sum_{i=1}^{10} X_{i j} \geq 1,(j=1,2, \cdots, 5)
$$

At the same time, one radar can illuminate a target at a time. We also obtain the relationship:

$$
\sum_{j=1}^{5} X_{i j}=1,(i=1,2, \cdots, 10)
$$

Assuming the coefficient is $\mathrm{A}_{\mathrm{ij}}$ which is the weighted detection probability of $M$ scans. The nonlinear programming search model [19] is as follows:

$$
\begin{aligned}
& \max f(x)=\sum_{j=1}^{5}\left(1-\prod_{i=1}^{10}\left(1-A_{i j} X_{i j}\right)\right) \\
& \text { s.t. }\left\{\begin{array}{l}
1-\prod_{i=1}^{10}\left(1-A_{i j} X_{i j}\right) \geq Q_{D}, j=1,2, \cdots, 5 \\
\sum_{j=1}^{5} X_{i j}=1, i=1,2, \cdots, 10 \\
\sum_{i=1}^{10} X_{i j} \geq 1, j=1,2, \cdots, 5
\end{array}\right.
\end{aligned}
$$

In nonlinear programming, the value of $X$ is a a continuous value. But in the model mentioned above, $\mathrm{X}$ is either 1 or 0 . Therefore, we construct function $Y_{i j} \in(0,2), X_{i j}=f \operatorname{floor}\left(Y_{i j}\right)$. Then, the model mentioned above can be transformed into the following form:

$$
\begin{aligned}
& \max f(y)=\sum_{j=1}^{5}\left(1-\prod_{i=1}^{10}\left(1-A_{i j} \text { floor }\left(Y_{i j}\right)\right)\right) \\
& \text { s.t. }\left\{\begin{array}{l}
1-\prod_{i=1}^{10}\left(1-A_{i j} \text { floor }\left(Y_{i j}\right)\right) \geq Q_{D}, j=1,2, \cdots, 5 \\
\sum_{j=1}^{5} \text { floor }\left(Y_{i j}\right)=1, i=1,2, \cdots, 10 \\
\sum_{i=1}^{10} \text { floor }\left(Y_{i j}\right) \geq 1, j=1,2, \cdots, 5
\end{array}\right.
\end{aligned}
$$

\section{SIMULATION ANALYSIS}

Firstly, we get the target weights shown in table 2:

TABLE II. TARGET WEIGHTS

\begin{tabular}{|c|c|c|c|c|c|}
\hline $\mathbf{W} \backslash \mathbf{T}$ & T1 & T2 & T3 & T4 & T5 \\
\hline $\mathbf{W}$ & 0.75 & 0.7 & 0.8 & 0.6 & 0.65 \\
\hline
\end{tabular}

The ESM divide the target area and the detection probabilities are calculated. Shown in table 3:

TABLE III. DETECTION PROBABILITIES

\begin{tabular}{|c|c|c|c|c|c|}
\hline $\begin{array}{c}\text { Detection } \\
\text { probability }\end{array}$ & T1 & T2 & T3 & T4 & T5 \\
\hline R1 & 0.8147 & 0.1576 & 0.6557 & 0.7060 & 0.4387 \\
\hline R2 & 0.9058 & 0.9706 & 0.0357 & 0.0318 & 0.3816 \\
\hline R3 & 0.1270 & 0.9572 & 0.8491 & 0.2769 & 0.7655 \\
\hline R4 & 0.9134 & 0.4854 & 0.9340 & 0.0462 & 0.7952 \\
\hline R5 & 0.6324 & 0.8003 & 0.6787 & 0.0971 & 0.1869 \\
\hline R6 & 0.0975 & 0.1419 & 0.7577 & 0.8235 & 0.4898 \\
\hline R7 & 0.2785 & 0.4218 & 0.7431 & 0.6948 & 0.4456 \\
\hline R8 & 0.5469 & 0.9157 & 0.3922 & 0.3171 & 0.6463 \\
\hline R9 & 0.9575 & 0.7922 & 0.6555 & 0.9502 & 0.7094 \\
\hline R10 & 0.9649 & 0.9595 & 0.1712 & 0.0344 & 0.7547 \\
\hline
\end{tabular}

Finally, the weighted detection probability is obtained. As shown in table 4:

TABLE IV. WEIGHTED DETECTION PROBABILITY

\begin{tabular}{|c|c|c|c|c|c|}
\hline $\begin{array}{c}\text { weighted } \\
\text { detection } \\
\text { probability }\end{array}$ & T1 & T2 & T3 & T4 & T5 \\
\hline
\end{tabular}




\begin{tabular}{|l|l|l|l|l|l|}
\hline R1 & 0.6110 & 0.1103 & 0.5246 & 0.4236 & 0.2632 \\
\hline R2 & 0.6794 & 0.6794 & 0.0286 & 0.0191 & 0.2290 \\
\hline $\mathbf{R 3}$ & 0.0953 & 0.6700 & 0.6793 & 0.1661 & 0.4593 \\
\hline $\mathbf{R 4}$ & 0.6850 & 0.3398 & 0.7472 & 0.0277 & 0.4771 \\
\hline $\mathbf{R 5}$ & 0.4743 & 0.5602 & 0.5430 & 0.0583 & 0.1121 \\
\hline R6 & 0.0731 & 0.0993 & 0.6062 & 0.4941 & 0.2939 \\
\hline R7 & 0.2089 & 0.2953 & 0.5945 & 0.4169 & 0.2674 \\
\hline R8 & 0.4102 & 0.6410 & 0.3138 & 0.1903 & 0.3878 \\
\hline R9 & 0.7181 & 0.5545 & 0.5244 & 0.5701 & 0.4256 \\
\hline R10 & 0.7237 & 0.6716 & 0.1370 & 0.0206 & 0.4528 \\
\hline
\end{tabular}

The above optimization model is simulated in MATLAB and we get the final result. As shown in table 5:

TABLE V. FINAL RESULT

\begin{tabular}{|c|c|c|c|c|c|}
\hline R\T & T1 & T2 & T3 & T4 & T5 \\
\hline R1 & 1 & 0 & 0 & 0 & 0 \\
\hline R2 & 0 & 1 & 0 & 0 & 0 \\
\hline R3 & 0 & 0 & 0 & 0 & 1 \\
\hline R4 & 0 & 0 & 1 & 0 & 0 \\
\hline R5 & 0 & 1 & 0 & 0 & 0 \\
\hline R6 & 0 & 0 & 1 & 0 & 0 \\
\hline R7 & 0 & 0 & 1 & 0 & 0 \\
\hline R8 & 0 & 0 & 0 & 0 & 1 \\
\hline R9 & 0 & 0 & 0 & 1 & 0 \\
\hline R10 & 1 & 0 & 0 & 0 & 0 \\
\hline
\end{tabular}

Through the simulation, the final results meet the conditions of the coverage requirements and minimum detection probability. The final search strategy and detection probability is shown in table 6 .

TABLE VI. FINAL SEARCH STRATEGY

\begin{tabular}{|c|c|c|c|}
\hline T & Weight & Radar & $\begin{array}{c}\text { Detection } \\
\text { probability }\end{array}$ \\
\hline T1 & 0.75 & $1 、 10$ & 0.8925 \\
\hline T2 & 0.7 & $2 、 5$ & 0.8590 \\
\hline T3 & 0.8 & $4 、 6 、 7$ & 0.9596 \\
\hline T4 & 0.6 & 9 & 0.5701 \\
\hline T5 & 0.65 & $3 、 8$ & 0.6690 \\
\hline
\end{tabular}

As shown, the weight of T3 is 0.8 and it is the biggest. The coresponding radars is 4,6 and 7 and the final weighted detection probability is 0.9596 . The weight of T4 is 0.6 and it is smallest. Only the $9_{\text {th }}$ radar is detecting it and the final detecion probability is 0.5701 which also is smallest in the five targets. In summary, the target weight value is greater, the number of the network detection radar is bigger and the corresponding detection probability is bigger also. The simulation results tally with the actual situation.

\section{SUMMARY}

In this paper, a new search strategy of netted surveillance radar is proposed. In section one, the scenario is proposed and the corresponding modle is built. In the following section, an improved multidimensional nonlinear algorithm is proposed to solve the problem and detailed steps are given. Finally, the feasibility of the method is verified through MATLAB simulation experiment. Through the analysis of the results, the new search strategy is proved reasonable. The content of this paper can provide theoretical guidance for the actual engineering application.

\section{ACKNOWLEDGMENT}

This paper is supported by the National Doctoral Foundation of China (20116102110026) and the Aerospace Technology Support Fund (2013-HT-XGD)

\section{REFERENCES}

[1] W. M. Siebert, "A radar detection philosophy," IEEE Trans. Inf. Theory,vol. 2, no. 3, pp. 204-221, Sep. 1956.

[2] M. Skolnik, Introduction to Radar Systems, 3rd ed. New York: Mc-Graw-Hill, 2002

[3] P. M. Woodward, Probability and Information Theory with Application to Radar. Norwood, MA: Artech House, 1953.

[4] H. L. V. Trees, Detection, Estimation, and Modulation Theory. New York: Wiley, 1968, vol. III.

[5] S. Haykin, J. Litva, and T. J. Shepherd, Radar Array Processing, $1^{\text {st }}$ ed. New York: Springer-Verlag, 1993.

[6] P.E. Howland, D. Maksimiuk and G. Reitsma, 'FM radio based bistatic radar', IEE Proc.- Radar Sornar Navig., Vol. 152, No. 3, June 2005.

[7] Hongbo Sun, Danny K.P. Tan, Yilong Lu, "Design and Implementation of an Experimental GSM Based Passive Radar", Radar Conference, Sept. 2003, pp 418- 422. (Stockholm, Sweden), pp. 1659-1662, May 2005.

[8] Danny K.P. Tan, Hongbo Sun, Yilong Lu, "Feasibility Analysis of GSM Signal for Passive Radar", Radar Conference, May. 2003, pp 425- 430 .

[9] C.J. Baker and H.D. Griffiths, 'Bistatic and Multistatic Radar Sensors for Homeland Security'. Ioannis Papoutsis, Chris J. Baker and Hugh D. Griffiths, 'Netted Radar The Ambiguity Function', 2005 Radar.

[10] C.J. Baker, H.D. Griffiths and I. Papoutsis, "Passive coherent location radar systems. Part2: Waveform properties", IEE Proc.Radar Sonar Navig., Vol. 152, No. 3, June 2005, pp 160- 168.

[11] D.K.P. Tan, H. Sun, Y. Lu, M. Lesturgie and H.L. Chan, 'Passive radar using Global System for Mobile communication signal: theory, implementation and measurements", IEE Proc.-Radar Sonar Navig., Vol. 152, No. 3, June 2005, pp 116- 123.

[12] Hugh D. Griffiths, Chris J. Baker, "Measurement and Analysis of Ambiguity Functions of Passive Radar Transmissions”, 2005 IEEE International Radar Conference, May. 2005, pp 321- 325.

[13] Peiguo Liu, Jibin Liu, "Analysis of passive targets detection using CDMA signal", VLSI Design and Video Technology, May. 2005, pp 408- 410.

[14] Eran Fishler, Rick S. Blum, ard J. Cimini, Jr. and Reinaldo A Valenzuela. Spatial Diversity in Radars-Models and Detection Performanc. IEEE Transactions on signal processing, vol. 54, no. 3, March 2006

[15] Li DanTong Tian-jue,Mao Sao-jie, Min Rong bao, " The Simulation for Electronic Countermeasures of the Radar Net and Modification of Radar Self-Protection Distance " Journal of system simulation.2006,18(5).

[16] He Pei, Jin Chang Jiang,Qu Xiang Ju, "Generation of radar detection space in the flight vehicle route planning" Flight Dynamics. 2001,19(4):78-84

[17] E. Fishier, et ai, Spatial diversity in radars-models and detection performance, IEEE Trans. on Signal Processing. Vol. 54, pp 823_838, No.3, March 2006.

[18] E.F. Knott, Radar cross section, in Radar Handbook. 3rded .• Ch.I4, McGraw-Hill, New York, 2008.

[19] Merrill I. Skolnik, "Introduction to radar system", third edition, $\mathrm{Mc}$

Graw Hill, 2001 